\title{
Spatial structure of the microbial community in sandy carbonate sediment
}

\author{
Ketil B Sørensen ${ }^{1,4, *}$, Brian Glazer ${ }^{2,3}$, Angelos Hannides ${ }^{3}$, Eric Gaidos ${ }^{1}$ \\ ${ }^{1}$ Department of Geology and Geophysics, POST 701, 1680 East West Road, University of Hawaii at Manoa, Honolulu, \\ Hawaii 96822, USA \\ ${ }^{2}$ NASA Astrobiology Institute, 213 PSB, 2565 McCarthy Mall, University of Hawaii at Manoa, Honolulu, Hawaii 96822, USA \\ ${ }^{3}$ Department of Oceanography, MSB, 1000 Pope Road, University of Hawaii at Manoa, Honolulu, Hawaii 96822, USA \\ ${ }^{4}$ Present address: Teknologiparken, Kongsvang Alle 29, Århus, Denmark
}

\begin{abstract}
The environmental conditions in permeable carbonate sands are in many ways different from those in fine-grained sediments, but little is known about how this affects the structure and composition of the microbial community. We studied the microbial community structure in relation to the geochemical zonation within a $4 \mathrm{~m}^{2}$ patch of a sandy carbonate sediment in Kane'ohe Bay, O'ahu, Hawaii. Porewater concentrations of oxygen and sulfide at depths between 15 and $52 \mathrm{~cm}$ were measured in situ using voltammetry, and sediment samples from 0 to $5 \mathrm{~cm}, 25$ to $35 \mathrm{~cm}$, and 70 to $80 \mathrm{~cm}$ depth were used to evaluate vertical and horizontal variation in the microbial community. Anoxic, suboxic (sulfide as well as oxygen below detection limit), or oxic conditions were measured in porewater from between 15 and $32 \mathrm{~cm}$ below the sediment/water interface, with no consistent depth pattern. All measurements below $32 \mathrm{~cm}$ indicated anoxic conditions, with sulfide concentrations ranging from $<10$ to about $200 \mu \mathrm{M}$. The microbial community revealed by denaturing gradient gel electrophoresis (DGGE) was homogeneous in the surface sediment, while large variations were observed at 25 to $35 \mathrm{~cm}$ depth, and smaller variations occurred at 70 to $80 \mathrm{~cm}$ depth. Richness analysis of clone libraries from each of the 3 depths indicated that the phylotype diversity was highest in the library from 25 to $35 \mathrm{~cm}$ depth. We suggest that the microbial community structure is correlated to local physico-chemical conditions in the sediment and that spatio-temporally heterogeneous redox conditions result in an increased microbial diversity. A monophyletic group of phylotypes that were highly divergent from any other sequences deposited in the GENBANK database was detected in the sediment. These phylotypes may represent chloroplasts or plastids associated with eukaryotes or a new lineage of Bacteria related to the Cyanobacteria. Using specific primers, members of the group were detected in sands from several coastal sites on the island of O'ahu.
\end{abstract}

KEY WORDS: Permeable sediment - Carbonate sediment · Microbial community composition · Voltammetry $\cdot$ Spatial variation

\section{INTRODUCTION}

The sandy sediments that cover large parts of the shallow ocean floor are important sites of nutrient cycling and may play an important role in global biogeochemical cycles (Huettel et al. 1998, Marinelli et al. 1998). Compared with fine-grained sediments in which porewater exchange is diffusion-limited, marine sands are characterized by high permeabilities, allow- ing for efficient advective exchange of particulate and dissolved materials with the overlying waters. Although sandy sediments usually contain little organic carbon and fewer microbial cells per volume than finegrained sediments, the hydraulically driven ventilation may support high rates of overall microbial metabolism (Buhring et al. 2005, Werner et al. 2006). The sandy, biogenic carbonate sediments that are widespread in tropical regions are characterized by high volume- 
specific surface areas compared to other types of sandy sediment, and may support relatively high numbers of prokaryotes (Yamamoto \& Lopez 1985, Wild et al. 2006). A number of studies have documented how microorganisms in these sediments efficiently mineralize organic material derived from primary producers on the reef (Rasheed et al. 2003, Wild et al. 2004, Werner et al. 2006), and measurements of nitrogen fixation as well as chlorophyll $a$ in surface layers of the sediments indicate that they may be sources of both bioavailable nitrogen and organic carbon (Shashar et al. 1994, Rasheed et al. 2004). Wave pumping and tidal currents drive efficient, temporally variable advective water transport within the sediment and across the sediment/water interface, and porewater redox conditions may be temporally dynamic down to depths of several tens of $\mathrm{cm}$ below the sediment surface (Falter \& Sansone 2000a,b). The unique physico-chemical conditions combined with other factors, like potentially high predation rates and high $\mathrm{pH}$ buffering capacity, may result in different microbial populations compared to fine-grained sediments.

Molecular techniques, including PCR amplification of DNA extracts followed by molecular fingerprinting and/or sequencing of phylotypes, have been used frequently to study the microbial community structure in marine sediments (e.g. Bowman \& McCuaig 2003, Asami et al. 2005). However, to our knowledge only a single study from the South Atlantic Bight has examined the phylogenetic composition of microbial communities in sandy sediments using genetic techniques and cloning/sequencing (Hunter et al. 2006). Vertical variation in molecular community fingerprints were observed in carbonate sediments from Heron Island, Australia (Hewson \& Fuhrman 2006), but the spatial structure of microbial communities in sandy carbonate sediments has not been studied specifically in relation to biogeochemistry, and the identities of major phylogenetic groups are unknown.

The objective of this study was to examine horizontal and vertical variations in microbial communities of permeable sandy carbonate sediment in relation to porewater geochemistry. The results suggest that spatio-temporal variations in porewater redox conditions below the sediment surface play a major role in structuring the microbial community by increasing local diversity and promoting spatial heterogeneity.

\section{MATERIALS AND METHODS}

Study site. Measurements and sampling was performed during 2005 at a patch reef (Moku o Lo'e or Coconut Island) in Kane'ohe Bay, O'ahu, Hawai'i, USA. The sediment at the sampling site consists of bio- genic carbonate rubble with grain sizes from $<1 \mathrm{~mm}$ to several $\mathrm{cm}$. Wave exposure varies with season, tide and wind conditions, but is generally moderate as the site is protected by the outer reef of Kane'ohe Bay. Tides are semi-diurnal with mean amplitudes of approximately $68 \mathrm{~cm} \mathrm{~d}^{-1}$ (Jokiel et al. 1993), and the high tide water depth at the sampling site is about $1 \mathrm{~m}$. Salinity is generally oceanic (34 psu) with occasional salinity depression from stream runoff. The annual range of surface water temperature in Kane'ohe Bay is approximately 19 to $28^{\circ} \mathrm{C}$, and the maximum observed wave height is about $50 \mathrm{~cm}$ (Falter \& Sansone 2000a,b).

Voltammetric measurements. Porewater concentrations of dissolved oxygen and sulfide were measured using voltammetry, as described previously (Brendel \& Luther 1995, Luther et al. 1998, Dollhopf et al. 2000, Glazer et al. 2006). The electrode setup consisted of an $\mathrm{Au} / \mathrm{Hg}$ working electrode $(0.1 \mathrm{~mm}$ diameter $)$, a silver/silver chloride $(\mathrm{Ag} / \mathrm{AgCl})$ reference electrode ( $0.5 \mathrm{~mm}$ diameter), and a platinum (Pt) counter electrode (0.5 mm diameter). All electrodes were custommade, sealed in commercially available polyetheretherketone (PEEK) tubing using epoxy (Brendel \& Luther 1995, Luther et al. 1998). Linear sweep, cyclic, or square wave voltammetry was used, scanning from $-0.1 \mathrm{~V}$ to $-1.85 \mathrm{~V}$ at a scan rate of 250 to $2000 \mathrm{mV} \mathrm{s}^{-1}$. Electrochemical conditioning of the electrode surface was performed between scans in order to remove any chemical species from the surface of the electrode. The electrodes were calibrated using a benchtop DLK-60 electrochemical analyzer (Analytical Instrument Systems) following established standardization procedures (Brendel \& Luther 1995). For field measurements, a DLK-60 analyzer was used with the addition of a portable DC power converter, allowing us to use the system with a $12 \mathrm{~V}$ DC deep-cycle battery.

Porewater geochemistry. Measurements were made in the field in October 2005. A modification of established porewater sampling techniques developed previously for highly permeable sediments (Falter \& Sansone 2000a) was used in combination with voltammetric measurements of sulfide and oxygen (Fig. 1). A pointed stainless steel rod (length $1 \mathrm{~m}$, diameter $1 \mathrm{~cm}$ ) and sleeve were driven into the sediment to the desired depth. Due to the high permeability of the sediment, porewater readily seeped into the sleeve upon removal of the rod. The sleeve was capped with a butyl rubber stopper fitted with 2 ports. Porewater was sampled through one of the ports using standard HPLC PEEK tubing and a $50 \mathrm{ml}$ syringe. The other port was used to insert a solid-state gold/amalgam ( $\mathrm{Au} / \mathrm{Hg})$ voltammetric electrode for simultaneous measurement of sulfide and oxygen concentrations in the porewater as it entered the system at the bottom of the sleeve. A similar electrode was placed inline with the sampling 


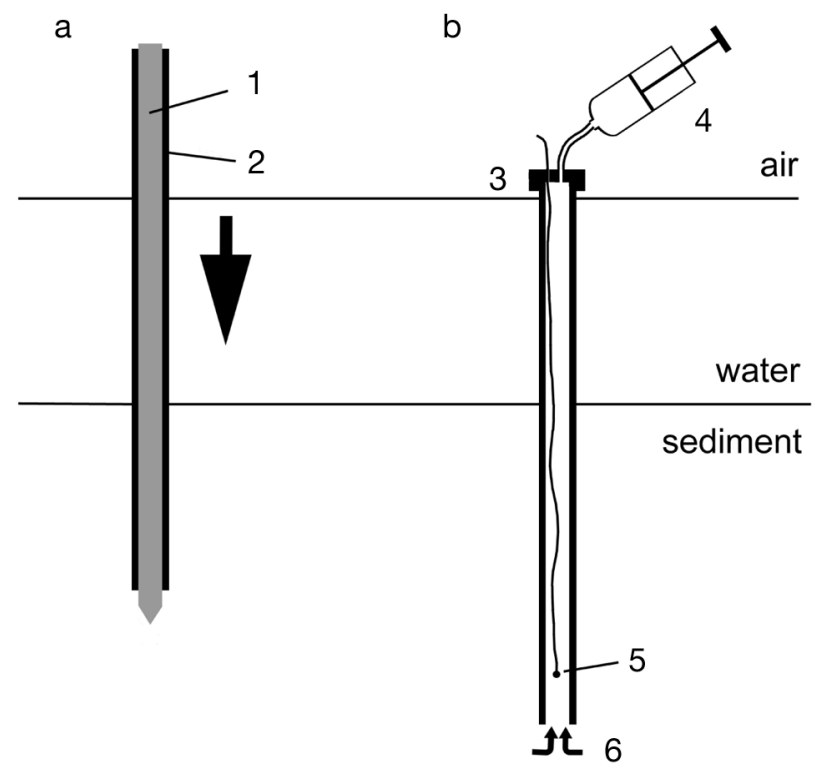

Fig. 1. Method used for porewater retrieval and characterization. (a) A $1 \mathrm{~m}$ long steel rod (1) and sleeve (2) were inserted into the sediment to the desired depth. The rod was then retrieved, leaving the sleeve in the sediment. (b) The sleeve was capped with a butyl rubber stopper (3) fitted with 2 ports. One of the ports was used for retrieval of porewater using a $50 \mathrm{ml}$ syringe (4), and the other for inserting an electrode (5) to the bottom of the sleeve for voltammetric measurements of sulfide and oxygen in the incoming porewater (6)

tube, permitting continuous monitoring of concentrations of oxygen and sulfide at the bottom of the sleeve and in the tubing as porewater was retrieved through the syringe. To completely flush the system during each measurement, about $200 \mathrm{ml}$ of water were withdrawn while continuously monitoring the electrode signal. Assuming a porosity of $50 \%$, the sampling volume corresponded to a sphere of radius $4.6 \mathrm{~cm}$. After each sampling, the sleeve was retrieved, and the sleeve/rod assembly was driven into the sediment at a new position. All measurements were performed within a $4 \mathrm{~m}^{2}$ area of reef flat.

Sediment sampling. Sediment samples for molecular analysis and cell counts were collected within the area used for geochemical measurements in November 2005. Surface sediment (approximately 0 to $5 \mathrm{~cm}$ below the sediment/water interface) was collected by scooping sediment into $50 \mathrm{ml}$ centrifuge tubes. Deeper sediment samples were collected by driving the assembled sleeve and rod into the sediment, retrieving the rod, and driving the sleeve another 10 to $20 \mathrm{~cm}$ into the sediment. Using this procedure, 10 to $20 \mathrm{~cm}$ long sediment cores were collected from the tip of the sleeve. Four samples (a, b,c, d) were collected directly from the sediment surface. These samples were all uniformly white and did not smell of sulfide. Three samples (e, f, g) were collected from between 25 and $35 \mathrm{~cm}$ below the sediment/water interface. Sample e had the same light color as the surface samples and did not smell sulfidic. Samples f and $g$ smelled sulfidic and were grey rather than white, indicating metal sulfide precipitates. Two samples (h and i) were collected from a depth of 70 to $80 \mathrm{~cm}$ in the sediment. Both these samples were dark grey and smelled of sulfide. These sediment samples were immediately transferred to $15 \mathrm{ml}$ centrifuge tubes and placed on ice. In the laboratory, each sample was gently homogenized by stirring with a spatula, and part of the sample was then frozen at $-80^{\circ} \mathrm{C}$ for later DNA extraction, while another part was fixed immediately for cell enumeration.

Cell counts. Weighed sediment samples of about $2 \mathrm{~g}$ were suspended in $3 \mathrm{ml}$ of filtered seawater $(0.22 \mu \mathrm{m}$, Osmonics filter) containing $2 \%$ formaldehyde and $2 \%$ acetic acid, and incubated at room temperature for $4 \mathrm{~h}$. Acetic acid was added to the fixation buffer to release surface-attached microorganisms from the carbonate grains (A. Rusch, pers. comm., Wild et al. 2006). This increased the cell counts by almost an order of magnitude compared with extractions performed without the addition of acid (data not shown). Each sample was placed in an ice bath and sonicated 5 times for $5 \mathrm{~s}$ (Fisher Scientific Sonic Dismembrator 100, output 7 to $8 \mathrm{~W}$ ). The sediment was allowed to settle for $5 \mathrm{~min}$ and the supernatant was transferred to a collection tube. Another $3 \mathrm{ml}$ of filtered seawater containing $2 \%$ acetic acid was added, the samples were sonicated and the supernatant collected as before. This was repeated another 3 times, resulting in a total supernatant volume of $15 \mathrm{ml}$. A volume of $100 \mu$ l of the water phase was collected with a pipette, mixed with $5 \mathrm{ml}$ sterile filtered phosphate buffered saline, PBS buffer (130 mM NaCl, $7 \mathrm{mM}$ $\mathrm{Na}_{2} \mathrm{HPO}_{4}, 3 \mathrm{mM} \mathrm{NaH} \mathrm{PO}_{4}, \mathrm{pH}$ 7.2), and filtered onto $25 \mathrm{~mm}$ black polycarbonate $0.22 \mu \mathrm{m}$ filters (Osmonics) mounted in a filtering system (Fisher Scientific). The filters were stained for 10 min with the DNA-specific stain (4,6-diamidino-2-phenylindole, DAPI) in a $0.2 \mathrm{mg} \mathrm{ml}^{-1}$ solution (Porter \& Feig 1980), and rinsed with $5 \mathrm{ml}$ of filtered PBS buffer before being mounted on a slide. The number of cells on each filter was quantified using an epifluorescence microscope (Olympus BX51). Putative Cyanobacteria and microalgae were identified by their bright red autofluorescence. Triplicate counting was performed on each of the sediment samples a to $\mathrm{i}$.

DNA extraction. DNA was extracted from the 9 sediment samples using a MOBIO Soil DNA Extraction Kit (Mobio). About $2 \mathrm{~g}$ of sediment were distributed into 4 screw-cap tubes and processed according to the manufacturer's instructions. The extraction products were readily amplifiable in $\mathrm{PCR}$ reactions and no further purification was necessary. 
Molecular fingerprinting. The extracted DNA samples were compared using nested PCR amplification of a fragment of the 16S rRNA gene followed by denaturing gradient gel electrophoresis (DGGE) (Muyzer et al. 1993). The approach with 2 rounds of PCR, each with a relatively low number of cycles, was taken in order to improve the quality of the final PCR product (Thompson et al. 2002). DNA extraction product $(0.3 \mu l)$ was added to a $50 \mu \mathrm{l}$ reaction mixture containing $1.5 \mathrm{mM}$ $\mathrm{Mg}^{++}, 1$ unit of FastStart Taq polymerase (Roche), $10 \mathrm{nmol}$ dNTP, $10 \mathrm{nmol}$ bovine serum albumine (Roche), and $50 \mathrm{nmol}$ of Bacteria-specific primers BAC8f (5'-AGRGTTTGATCCTGGCTCAG-3') and BAC1492r (5'-CGGCTACCTTGTTACGACTT-3'). A total of 20 PCR cycles were performed in an ABI 7000 thermocycler, with each cycle consisting of $45 \mathrm{~s}$ of denaturing at $94^{\circ} \mathrm{C}$, a $45 \mathrm{~s}$ annealing step at $56^{\circ} \mathrm{C}$, and a 2 min elongation step at $72^{\circ} \mathrm{C}$. Subsequently, $1 \mu \mathrm{l}$ of the reaction product was transferred to a fresh reaction mixture and amplified, as before, in PCR cycles with primers GC-BAC341f (5'-CGCCCGCCGCGCGCGGC GGGCGGGGCGGGGGCACGGGGGGCCTACGGGR GGCAGCAG-3') and BAC521r (5'-ACCGCGGCTGCTGGCAC-3') (all primers from Integrated DNA Technologies). The quality and concentration of the product in each reaction was evaluated on $2 \%$ agarose gels. The PCR products were separated in a DGGE1001 denaturing gradient gel electrophoresis system (C.B.S. Scientific Company). Stock solutions representing $0 \%$ and $100 \%$ denaturing agent were prepared. The $0 \%$ solution consisted of $10 \%$ acrylamide/bisacrylamide (37.5:1) in $0.5 \times$ Tris/acetic acid/EDTA buffer (TAE), and the $100 \%$ solution consisted of $10 \%$ acrylamide/bis-acrylamide, $420 \mathrm{~g} \mathrm{l}^{-1}$ urea, and $400 \mathrm{ml}$ $\mathrm{l}^{-1}$ formamide in $0.5 \times$ TAE. The DGGE gels were cast using mixtures of these stock solutions in denaturing gradients with $40 \%$ denaturing agent in the top and $70 \%$ in the bottom of the gels. Similar amounts of DNA (between 10 and $25 \mu \mathrm{l}$ of the PCR product, depending on concentration) were loaded in each well, and the gels were run for $18 \mathrm{~h}$ at $120 \mathrm{~V}$ and $60^{\circ} \mathrm{C}$. The gels were stained for $15 \mathrm{~min}$ in $0.5 \times \mathrm{TAE}$ buffer containing 1:10 000 SYBR-green I (Cambrex Bio Science) and evaluated on a UV transilluminator (Spectroline).

Comparison of DGGE band patterns. The absence or presence of the $i$ th band in the $j$ th lane on the DGGE gel was registered by assigning a score $S_{x}^{i}$ of 0 (absence) or 1 (presence). The matrix containing these scores was used to calculate a distance matrix representing the differences in band patterns. The distance between lanes (samples) $x$ and $y$ was calculated according to:

$$
D_{x y}=\mathrm{N}^{-1} \sum_{i=1}^{\mathrm{N}}\left(S_{x}^{i}-S_{y}^{i}\right)^{2}
$$

where $\mathrm{N}$ was the total number of different bands on the gel. Finally, a distance tree (Neighbor Joining) was constructed based on the calculated distance matrix using the programs NEIGHBOR, RETREE, and DRAWGRAM of the PHYLIP software package (Felsenstein 1988).

Cloning and sequencing. Clone libraries were constructed from samples a (0 to $5 \mathrm{~cm}$ depth in sediment), e (25 to $35 \mathrm{~cm}$ depth), and h (70 to $80 \mathrm{~cm}$ depth). PCR reactions were performed as described above (but with 30 cycles) using primers BAC8f and BAC1492r, or with general prokaryotic primers GEN536f (5'-CAGCMGCCGCGGTAATWC-3') and GEN1392r (5'-ACGGGCGGTGTGTRC-3'). PCR products were gel-purified on $1 \%$ low-melting-point agarose gels. About $50 \mathrm{ng}$ of PCR product was loaded on the gel, run for $30 \mathrm{~min}$ at $70 \mathrm{~V}$, and stained with ethidium bromide. DNA was extracted from the gel using the QIAEX ${ }^{\circledR}$ II gel extraction kit according to the manufacturer's instructions (QIAGEN). The purified DNA samples were A-tailed to improve cloning efficiency by mixing the purified PCR product $(40 \mu \mathrm{l})$ with $5 \mu \mathrm{l}$ deoxyadenosine triphosphate $(2 \mathrm{mM}), 5 \mu \mathrm{l} 10 \times \mathrm{PCR}$ reaction buffer, and 1 unit of FastStart Taq DNA polymerase (Roche). The mixture was incubated at $72^{\circ} \mathrm{C}$ for $10 \mathrm{~min}$, extracted with phenol/chloroform/isoamylalcohol (25:24:1), and centrifuged at $6000 \times g$ for $5 \mathrm{~min}$. The aqueous phase was then transferred to a fresh microcentrifuge tube and precipitated with 2.5 volumes of ethanol and 0.1 volumes of $5 \mathrm{M} \mathrm{NaCl}$. After centrifugation (10 min, $10000 \times g, 4^{\circ} \mathrm{C}$ ), the pellet was washed once with $20 \mu \mathrm{l}$ $70 \%$ ethanol, air-dried, and resuspended in $4 \mu \mathrm{l}$ water. The purified and A-tailed PCR products were ligated into a pGEM ${ }^{\circledR}$-T vector (Promega) and transformed by heat shock $\left(42^{\circ} \mathrm{C}, 50\right.$ s) into JM109 cells (Promega) according to the manufacturer's specifications. Sequence data were obtained from the Center for Genomics, Proteomics, and Bioinformatics at the University of Hawaii using sequencing primers M13F (5'-GTAAAACGACGGCCAG-3') and M13R (5'-CAGGAAACAGCTATGAC-3'). Forward and reverse reads were assembled, aligned, and checked for chimeric structures using BELLEROPHON (Huber et al. 2004).

Phylogenetic analysis and design of specific PCR primers. Sequence data were compared against the Genbank 16S rRNA database using BLAST (Altschul 1997). The sequences were aligned using CLUSTAL $W$ (Thompson et al. 1994) followed by manual alignment in Bioedit 7.0.0 (available at www.mbio.ncsu.edu/ BioEdit/bioedit.html). Phylogenetic trees were constructed from the alignment sequences using programs of the PHYLIP package to calculate Jukes-Cantor distance matrices followed by Neighbor Joining. Bootstrapping (1000 resamplings) was performed in order to validate the tree topology. Primers were designed based on 
the clone libraries obtained using PRIMROSE (Ashelford et al. 2002), and the specificity of each primer was subsequently tested by screening against the RDP II database using <PROBE MATCH> (available at rdp.cme. msu.edu).

Sequence accession numbers. The phylotypes found during this study can be downloaded from the NCBI homepage (www.ncbi.nlm.nih.gov). The accession numbers are EF208619 to EF208746.

\section{RESULTS}

\section{Porewater geochemistry}

As described in 'Materials and Methods', the sleeve and rod were withdrawn and reinserted into the sediment to a new position between each measurement. Consequently, the results described below represent a set of horizontally separated point measurements, and not an actual porewater profile. Most of the voltammetric measurements indicated the presence of dissolved sulfide and/or oxygen in the porewater. Concentrations of other electrochemically active compounds like organically bound Fe(III) compounds, dissolved $\mathrm{Fe}^{2+}$, $\mathrm{Mn}^{2+}$, thiosulfate and sulfite were always below detection limits. The results of the voltammetric measurements are summarized in Fig. 2 where sulfide and oxygen concentrations are plotted. Sulfide was detected in all but 4 measurements from between 17 and $31 \mathrm{~cm}$ depth. One measurement at $22 \mathrm{~cm}$ below the sediment surface indicated a concentration of $55 \mu \mathrm{M}$ oxygen and no dissolved sulfide. Three measurements from 17, 22,

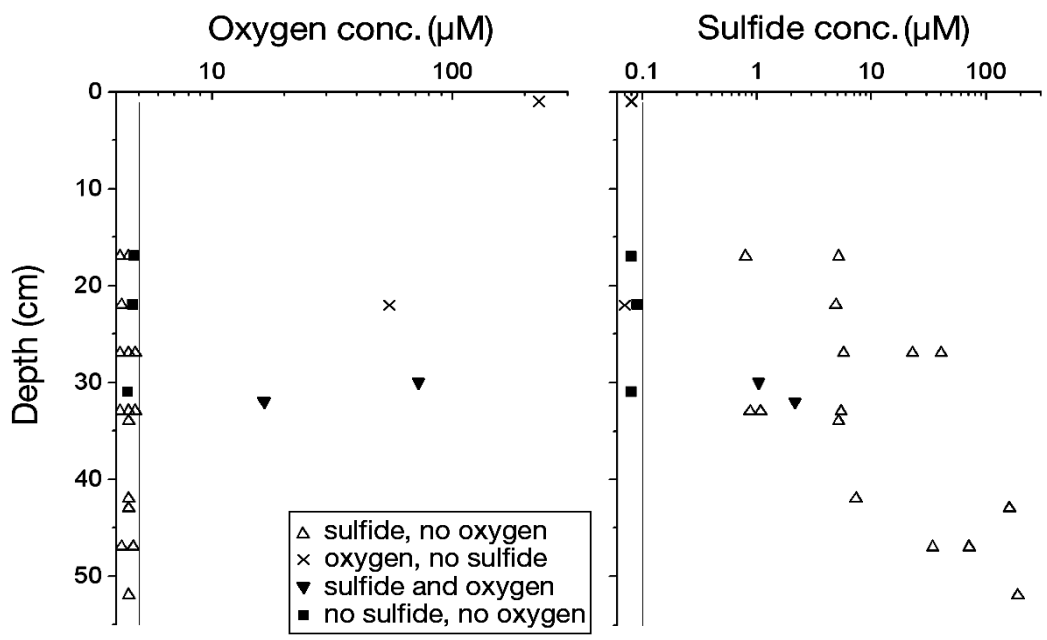

Fig. 2. Voltammetric measurements of oxygen and sulfide in the porewater. Symbols (see key in Fig.) indicate measurements in which only sulfide $(\Delta)$, only oxygen $(\times)$, both sulfide and oxygen $(\boldsymbol{\nabla})$, and neither sulfide nor oxygen $(\boldsymbol{\square})$ was detected. Detection limits (5 $\mu \mathrm{M}$ for oxygen, $0.1 \mu \mathrm{M}$ for sulfide) are shown as vertical lines in each panel. Note the logarithmic concentration axes. conc.: concentration and $31 \mathrm{~cm}$ depth failed to detect either sulfide or oxygen. Finally, sulfide and oxygen were detected contemporaneously in the porewater in 2 measurements from 30 and $32 \mathrm{~cm}$ depth. Generally speaking, dissolved sulfide concentrations increased with depth. Thus, with few exceptions (2 values from $27 \mathrm{~cm}$ ) concentrations measured at depths shallower than $42 \mathrm{~cm}$ in the sediment were lower than $10 \mu \mathrm{M}$, while deeper measurements were between 34 and $188 \mu \mathrm{M}$.

\section{Cell counts and morphology}

We observed mostly small $(<2 \mu \mathrm{m})$ coccoid, oval, or rod-shaped morphotypes. Cyanobacteria and microalgae accounted for $<1 \%$ of the cells observed in the surface layer, and even less than this figure in the sediment below. The average cell numbers in the 4 samples of surface sediment were $8.4 \pm 1.3 \times 10^{8} \mathrm{~g}^{-1}$. The number of cells decreased with depth to $1.4 \pm 0.5 \times 10^{8}$ in the 3 samples from 25 to $35 \mathrm{~cm}$ depth and $0.7 \pm 0.4 \times$ $10^{8}$ in the 2 samples from 70 to $80 \mathrm{~cm}$ depth.

\section{DGGE analysis (gel electrophoresis)}

Band patterns of amplified bacterial genes for $16 \mathrm{~S}$ rRNA from each of the sediment samples are shown in Fig. 3. Three bands dominated in all 4 surface samples (b1, b2 and b3), but were absent or much fainter in samples from deeper in the sediment. The 3 samples from 25 to $35 \mathrm{~cm}$ also shared several dominant bands, but their relative intensity varied greatly (b4 through b7). The 2 samples from 70 to $80 \mathrm{~cm}$ shared some dominant bands with the $35 \mathrm{~cm}$ depth samples (b4 and b5), but again the relative intensity among the dominant bands varied. Distance matrices based on absence or presence of bands were constructed and used for the comparison of band patterns (Fig. 4). Mutual distances among the surface samples were less than 0.11. In contrast, the deeper samples were much more heterogeneous, with mutual distances varying from 0.20 to 0.45 .

\section{Clone library construction and sequencing}

A total of 96 clones obtained with the Bacteria-specific BAC8f/BAC1492r primer set and 144 clones obtained with the universal GEN535f/GEN1392r primers 


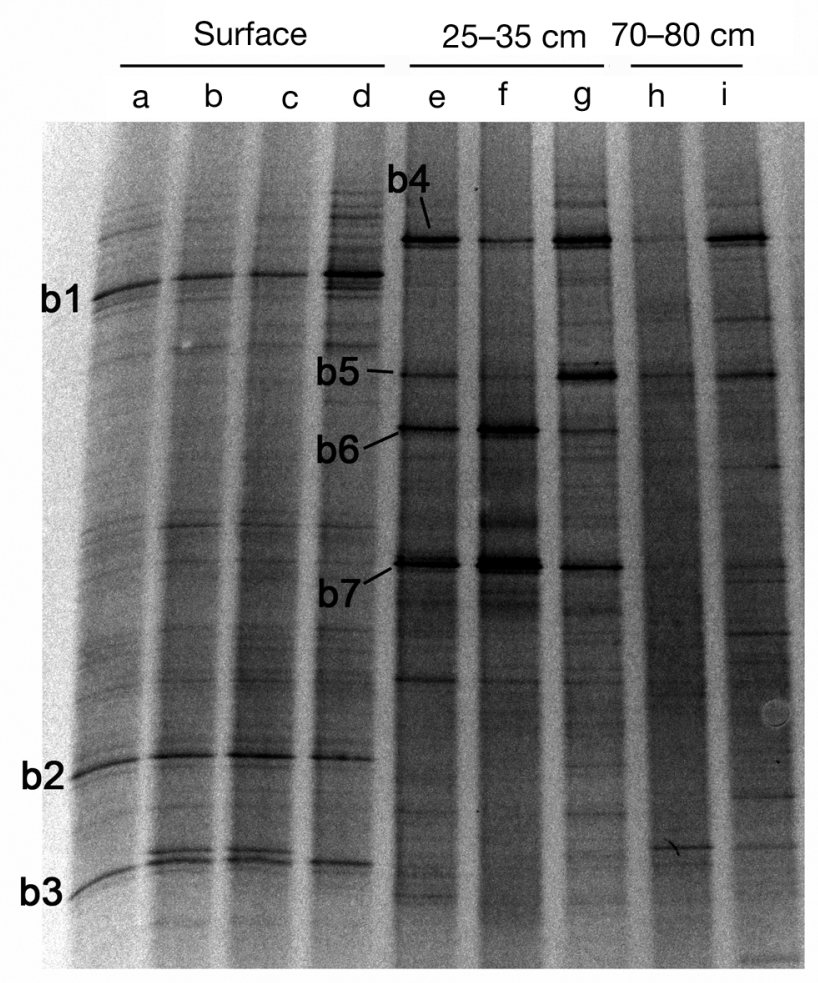

Fig. 3. DGGE gel run with PCR-amplified bacterial 16S rRNA from 9 sediment samples. Lanes a to $d$ are from the surface layer, Lanes e to $\mathrm{g}$ are from $35 \mathrm{~cm}$ below the sediment/water interface, and Lanes $\mathrm{h}$ and $\mathrm{i}$ are from $75 \mathrm{~cm}$ below the sediment/water interface. Dominant bands (b1 to b7) mentioned in the text are indicated

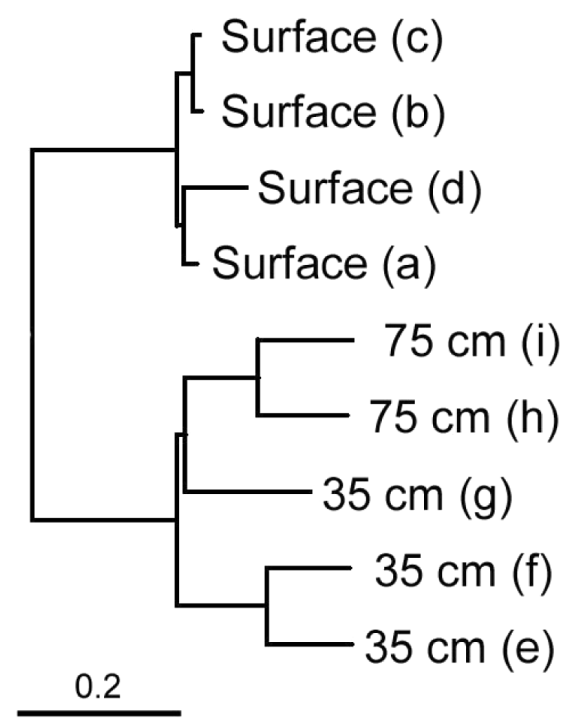

Fig. 4. UPMGA tree based on matrix of distances calculated from the differences in DGGE band patterns between sediment samples a through i in Fig. 3. Distances were calculated as explained in 'Materials and Methods' (see Eq. 1) and the tree was constructed by Neighbor-Joining. Scale bar indicates a $D$ (genetic distance) value of 0.2 were processed for sequencing, yielding a net total of 188 sequences. Of these, 13 were disregarded as possible chimeras. The resulting 175 sequences were distributed among 128 different phylotypes ( $\leq 98 \%$ similarity). Neighbor-joining trees indicating the phylogenetic position of the phylotypes are shown in Figs. 5 to 8, and the numbers of phylotypes affiliated with different groups of prokaryotes are summarized in Table 1.

\section{Proteobacteria}

Among the phylotypes detected were diverse Gammaproteobacteria including members of the 'Chromatiales', the 'Legionellales', the Enterobacteriaceae, and the Pseudomonadales, as well as several deeply rooted groups of organisms of which no representatives have yet been cultured (Fig. 5). Most cultured members of the 'Chromatiales' are phototrophic sulfur oxidizers that grow in the presence of light and reduced sulfur species. A few chemolithotrophic genera are known as well, including Nitrococcus and Thioalkalivibrio (Sorokin et al. 2001). The Pseodomonadales, Enterobacterales, and 'Legionellales' consist of aerobic or facultatively anaerobic chemoorganotrophs. A number of phylotypes retrieved from the 25 to $35 \mathrm{~cm}$ and 70 to $80 \mathrm{~cm}$ samples were affiliated with the Deltaproteobacteria (Fig. 6). Most of the deltaproteobacterial phylotypes from the 25 to $35 \mathrm{~cm}$ sample fall within the order Мухоcoccales, consisting of aerobic or facultatively anaerobic chemoorganotrophs (Sanford et al. 2002). In contrast, deltaproteobacterial phylotypes from the $75 \mathrm{~cm}$ sample were related to the 'Desulfobacterales' or the 'Syntrophobacteraceae', which include anaerobic sulfatereducing and syntrophic organisms. A number of phylotypes affiliated with the 'Rhodobacterales', the Caulobacterales, the Sphingomonadaceae, and the Rhodospirillaceae were detected in the sediment (Fig. 6). The Caulobacterales and Sphingomonadaceae consist mainly of chemoorganotrophic, aerobic organisms. Members of the Rhodospirillaceae and the 'Rhodobacterales' are notoriously versatile in their metabolism, and several genera are able to alternate between phototrophic and chemoorganotrophic growth (Imhoff 2001, Guyoneaud et al. 2002). A few clones were affiliated with the 'Burkholderiales', which includes phototrophs, chemolithotrophs, methylotrophs, chemoorganotrophs, and nitrogen-fixing organisms, as well as several human, animal, and plant pathogens.

\section{Cyanobacteria and relatives}

A total of 6 clones representing 3 phylotypes were affiliated with known groups of Cyanobacteria 


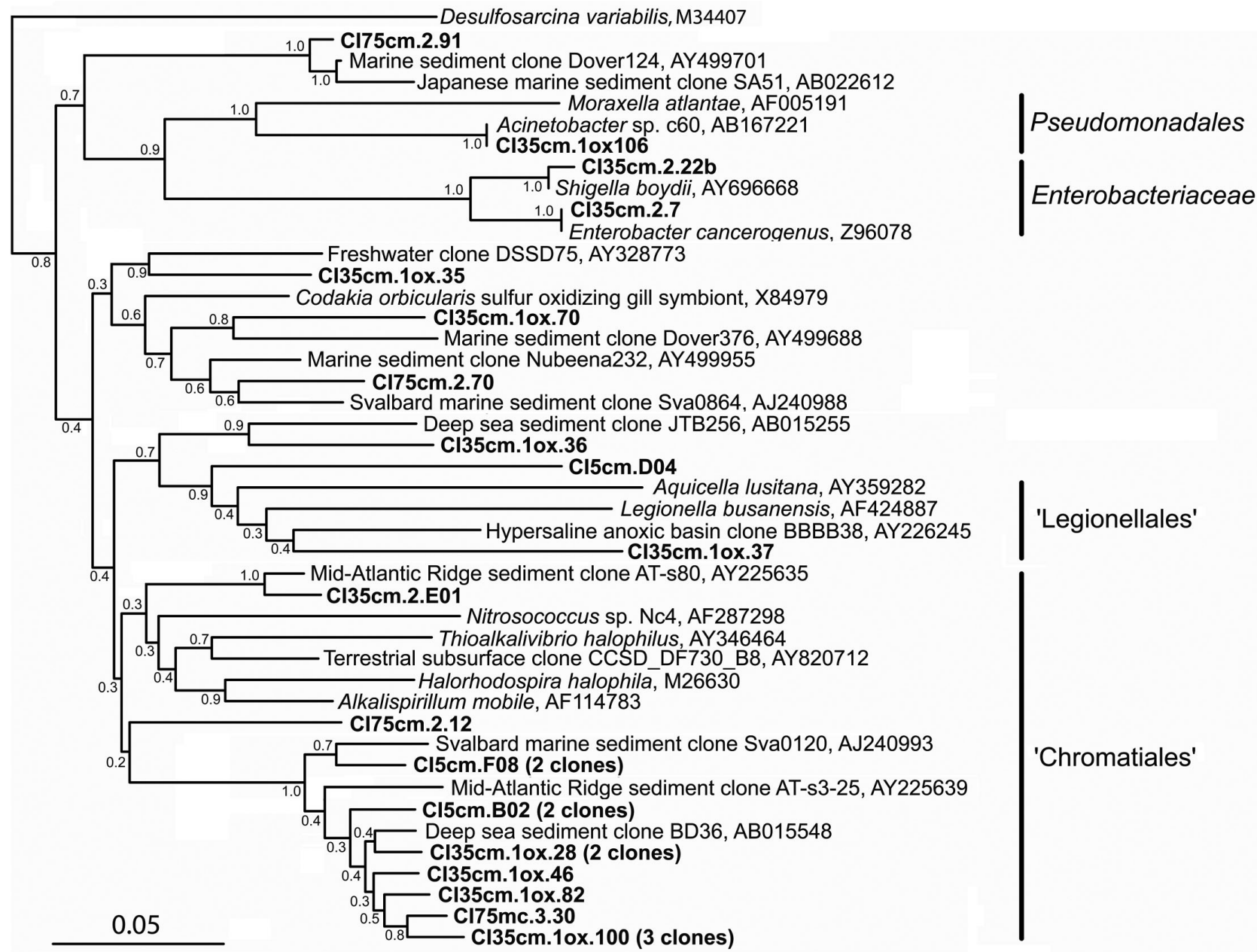

Fig. 5. Phylogenetic tree including phylotypes affiliated with the Gammaproteobacteria. Distance matrices were calculated by the Jukes-Cantor method and the tree was constructed by Neighbor-joining. Bootstrap values are from 1000 resamplings. Scale bar indicates $5 \%$ difference in nucleotide sequence. Phylotypes from the present study are in bold

(Fig. 7a). These were all retrieved from the surface. Another group of phylotypes found at all 3 depths formed a monophyletic cluster branching near the root of the Cyanobacteria. These phylotypes were highly divergent from any sequences deposited previously in the GENBANK database. A set of primers (5'-ATGGGCACTCGATGCTGC-3' and 5'-GAAGTGGGGCCGGGTTTA-3') was designed to specifically amplify members of this cluster. This primer set targeted an approximately $500 \mathrm{bp}$ region in the last half of the 16S rRNA gene. Cloning and sequencing of a PCR product obtained with these primers confirmed the specificity, as all 95 sequences were affiliated with the cluster. Using the specific primer set, the group was detected in sandy sediment samples from between 0 and $2 \mathrm{~m}$ water depth at several shoreline locations on O'ahu.

\section{Other groups of Bacteria}

A total of 16 phylotypes were affiliated with the 'Chloroflexi' (Fig. 7a). The closest cultured relatives of Coconut Island 'Chloroflexi' are non-phototrophic genera including Dehalococoides, Anaerolinea and Sphaerobacter. Related environmental clones have previously been retrieved from coastal marine sediments (Bowman \& McCuaig 2003, Asami et al. 2005). A total of 15 clones representing 12 phylotypes were affiliated with the class Planctomycea (Fig. 7b). Phylogenetically, they clustered within the genera Planctomyces or Pirellula, or among deeply rooted groups of environmental clones without close relatives in culture. Cultured strains of Planctomycea include aerobic or facultative anaerobic chemoheterotrophs, and some are capable of nitrate reduction (Hirsch \& Muller 1985, Schlesner 1986). A number of acidobacterial phylotypes 


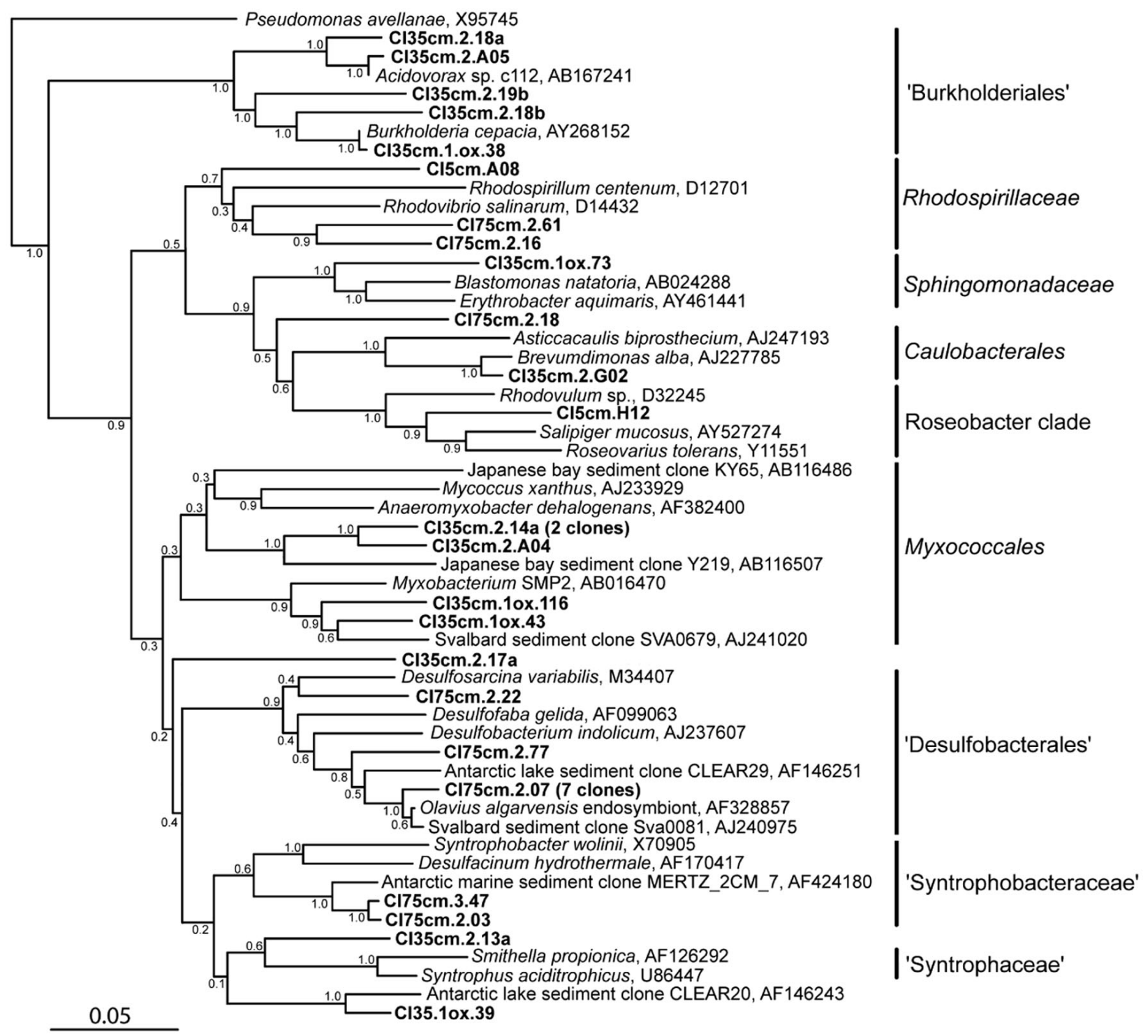

Fig. 6. Neighbor-joining phylogenetic tree for alpha-, beta-, and deltaproteobacterial phylotypes. Parameters as for Fig. 5

were detected, particularly in the sample from 25 to $35 \mathrm{~cm}$ depth. The surface layer of the sediment was rich in phylotypes affiliated with the 'Sphingobacteriales' and the 'Flavobacteriales'. Cultured representatives of these orders are heterotrophic, mostly aerobic organisms. Other groups detected in lower numbers in the sediment included the Actinobacteria, Verrucomicrobia, Nitrospira, the OP8 group, Chlamydia, and Firmicutes (Table 1).

\section{Archaea}

Both Eury- and Crenarchaeotal phylotypes were retrieved from the sediment (Fig. 8). Most of the archaeal clones from the $35 \mathrm{~cm}$ sample were affiliated with Marine Group I (MGI), a group of Crenarchaeota which is widely distributed in ocean waters and sediments (Fuhrman et al. 1992). Recently, a strain of MGI was isolated and shown to grow by aerobic oxidation of ammonium to nitrite (Könneke et al. 2005). Most of the clones from $75 \mathrm{~cm}$ depth belonged to the Terrestrial Miscellaneous Crenarchaeal Group (TMCG) (Takai et al. 2001). Euryarchaeal clones affiliated with Marine Group III (MGIII) were also detected at $75 \mathrm{~cm}$ depth (Delong 1998). The TMCG and MGIII consist solely of environmental sequences.

\section{Diversity estimates}

The total diversity in each sediment sample was evaluated by calculating $\mathrm{S}_{\mathrm{Chao} 1}$ estimators (Kemp \& Aller 


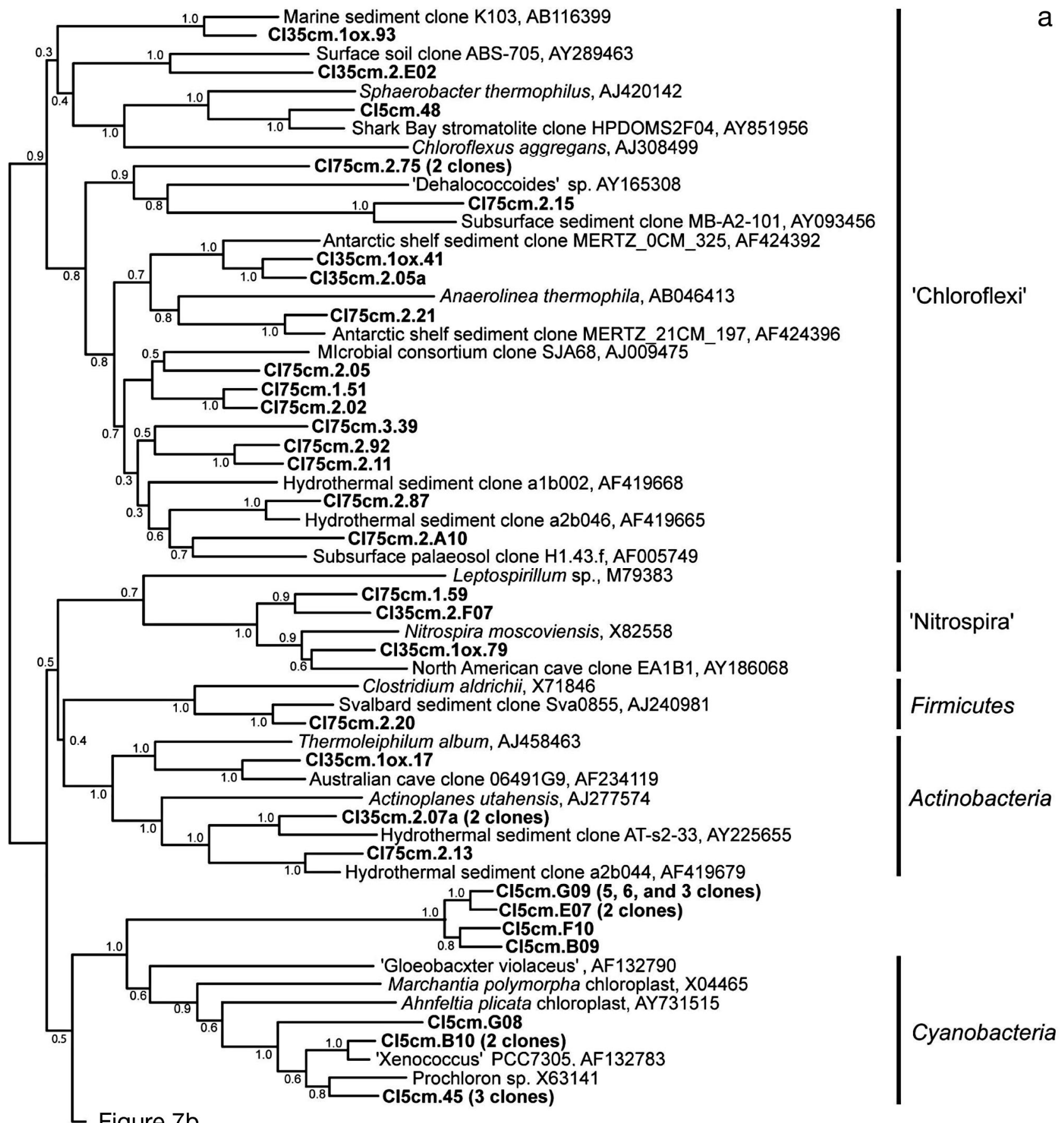

Figure $7 b$

Fig. 7. (Above and next page.) (a,b) Neighbor-Joining phylogenetic tree for bacterial phylotypes not affiliated with the Proteobacteria. Parameters as for Fig. 5

2004). The estimated phylotype richness in the clone library from the surface sample was 33, with a $95 \%$ confidence interval between 24 and 68. In the clone libraries from 25 to 35 and 70 to $80 \mathrm{~cm}$ depth, the numbers of phylotypes were estimated to be 338 (95\% confidence interval 163 to 798) and 187 (95\% confi- dence interval 104 to 393), respectively. To test the robustness of these numbers, similar calculations were performed on randomly selected subsets containing $1 / 4$, $1 / 2$, or $3 / 4$ of each clone collection (Kemp \& Aller 2004). The resulting richness saturation curves are shown in Fig. 9. In the case of the surface sample, the richness es- 


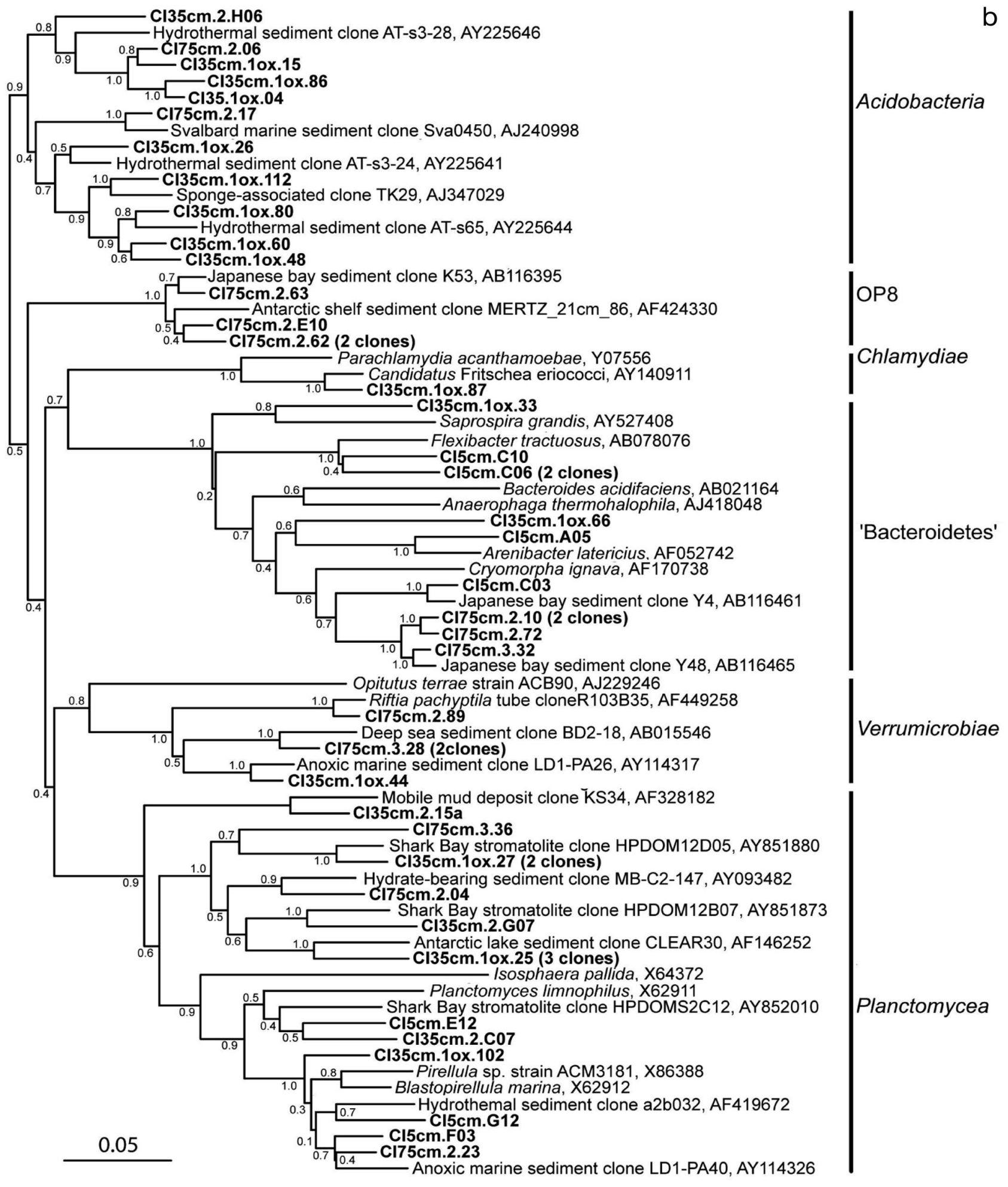

Fig. 7 (continued)

timator remained constant when half (16 of 33) or more of the clones were included in the calculation. This suggests that the estimated total number of phylotypes is reasonable. The same was the case for the clone library from 70 to $80 \mathrm{~cm}$ depth. On the other hand, richness estimates of the clone library from 25 to $35 \mathrm{~cm}$ depth did not reach a plateau, indicating that sequencing of more clones would increase the richness estimate. 


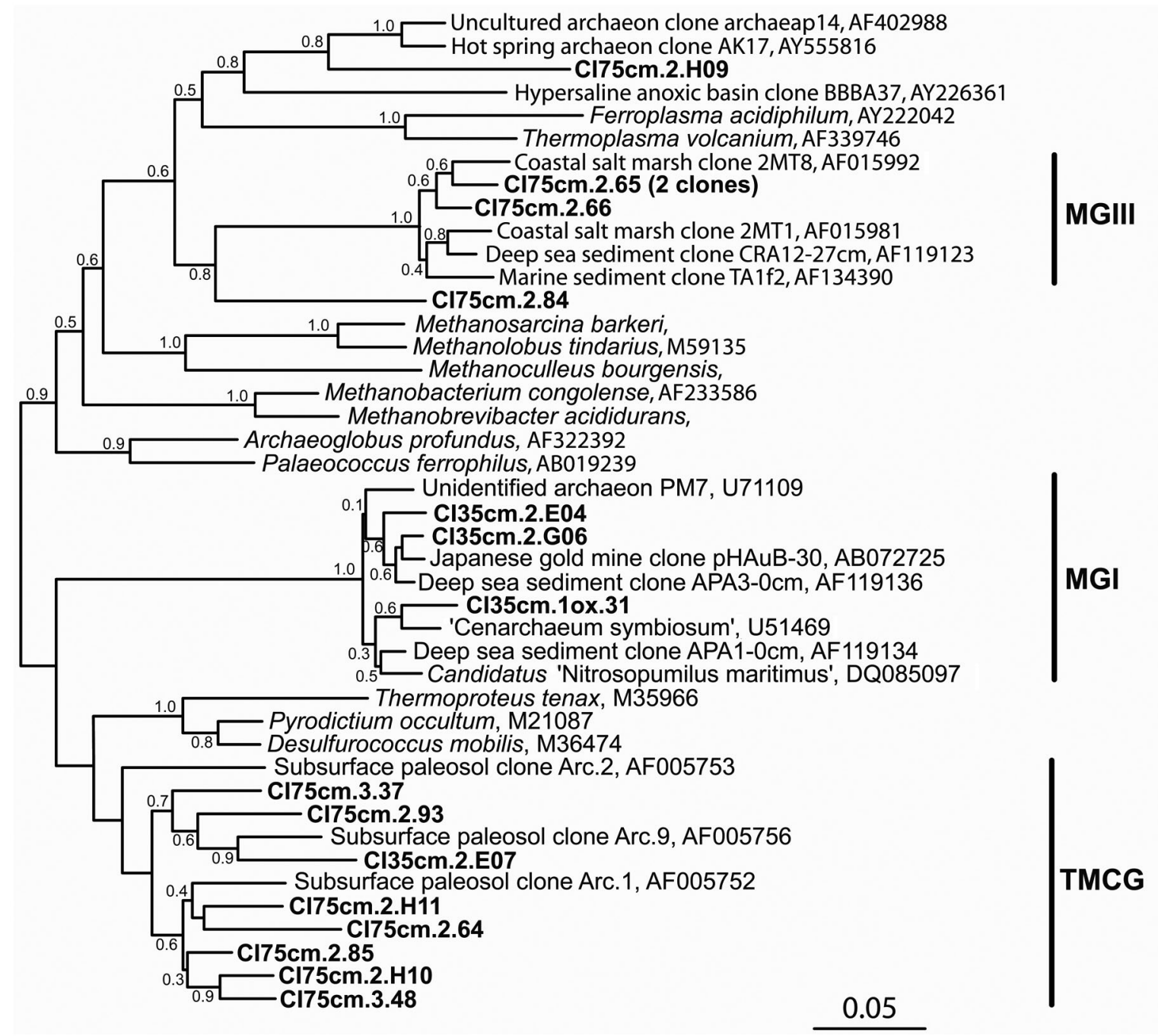

Fig. 8. Neighbor-Joining phylogenetic tree for archaeal phylotypes. Parameters as for Fig. 5. MGI/III: Marine Group I/III; TMCG: Terrestrial Miscellaneous Crenarchaeotal Group

\section{DISCUSSION}

\section{Porewater conditions}

Previous studies have documented the facile retrieval of porewater samples through tubes inserted into permeable sediments (Falter \& Sansone 2000a). In the current study, this technique was combined with simultaneous voltammetric measurements of porewater oxygen and sulfide concentrations. The fact that oxygen remained below the detection limit in most of the measurements indicates that little or no contamination by atmospheric air or surface water occurred. In a few measurements, oxygen and sulfide were detected simultaneously, albeit in low concentrations. This suggests either that sulfide and oxygen coexisted in the sediment, or that porewater from adjacent oxic and sulfidic zones was mixed during withdrawal of the sample. At the observed concentrations of reactants (1 to $2 \mu \mathrm{M}$ dissolved sulfide, 10 to $70 \mu \mathrm{M} \mathrm{O}_{2}$ ) the rate of chemical sulfide oxidation with oxygen is 10 to $50 \mathrm{nM} \mathrm{h}^{-1}$ (Chen \& Morris 1972) and the corresponding turnover time of sulfide is between 20 and $200 \mathrm{~h}$. Thus, it may be possible for these 2 mutually reactive porewater constituents to coexist at micromolar concentrations in zones where porewater advection transports oxygen-containing water into layers harboring sulfatereducing organisms.

A few samples contained neither detectable sulfide nor oxygen. In contrast to the simultaneous detection discussed above, such a result is unlikely to be produced by mixing of oxygen- and sulfide-containing water during sampling, as the 2 ingredients would have to be mixed in equimolar amounts and react almost instantaneously to near extinction. This result thus strongly suggests the presence of suboxic condi- 
Table 1. Abundance of phylotypes affiliated with different groups of organisms at the 3 sediment depths examined. -: none detected

\begin{tabular}{|lccc|}
\hline \multirow{2}{*}{ Affiliation } & \multicolumn{4}{c|}{ Number of clones } \\
\cline { 2 - 4 } & $\begin{array}{c}\text { Sample a } \\
(0-5 \mathrm{~cm})\end{array}$ & $\begin{array}{c}\text { Sample e } \\
(25-35 \mathrm{~cm})\end{array}$ & $\begin{array}{c}\text { Sample } \mathrm{h} \\
(70-80 \mathrm{~cm})\end{array}$ \\
\hline Proteobacteria & & & \\
$\quad$ Alpha- & 2 & 2 & 3 \\
Beta- & - & 5 & - \\
$\quad$ Gamma- & 5 & 15 & 4 \\
Delta- & - & 8 & 11 \\
'Chloroflexi' & 1 & 4 & 12 \\
Cyanobacteria & 6 & - & - \\
Unidentified & 9 & 6 & 3 \\
Cyanobacteria relatives & & & \\
Firmicutes & - & - & 1 \\
Actinobacteria & - & 3 & 1 \\
'Nitrospira' & - & 2 & 2 \\
Acidobacteria & - & 9 & 2 \\
OP8 & - & - & 3 \\
Planctomycea & 3 & 9 & 3 \\
Verrumicrobiae & - & 1 & 3 \\
Chlamydiae & - & 1 & - \\
'Bacteroidetes' & 5 & 3 & 4 \\
Archaea & - & 4 & 11 \\
Others & 2 & 4 & 3 \\
Total & 33 & 76 & 66 \\
\hline
\end{tabular}

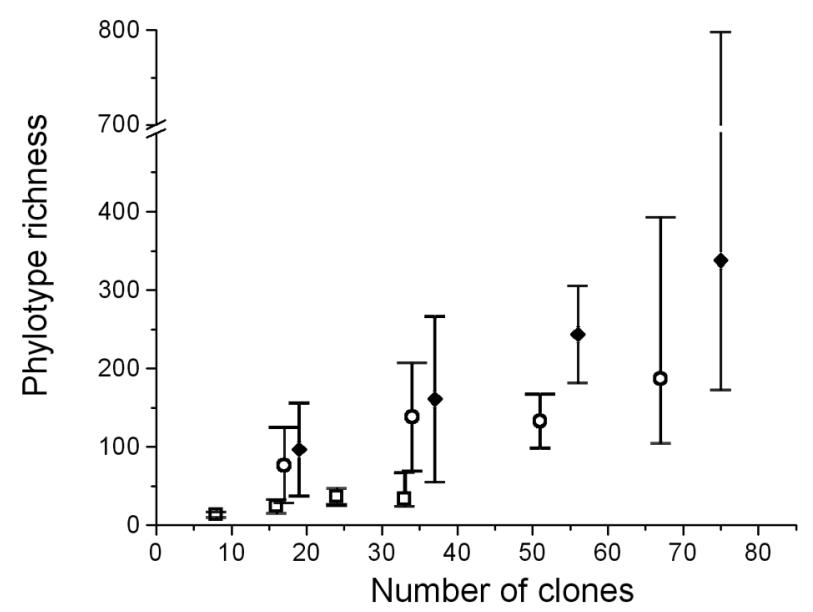

Fig. 9. $\mathrm{S}_{\text {Chao1 }}$ estimates (Kemp \& Aller 2004) of total bacterial diversity calculated from the 3 clone libraries and from randomly sampled subsets of about $1 / 4,1 / 2$, and $3 / 4$ of each of the clone libraries (10 resamplings). Each point represents the mean of 10 resamplings from the $5 \mathrm{~cm}$ depth sample ( $\square$ ), $35 \mathrm{~cm}$ depth sample ( ), or $75 \mathrm{~cm}$ depth sample (O). Error bars for points representing the full datasets are $95 \%$ CI limits. Error bars at points including $1 / 4,1 / 2$, or $3 / 4$ of a dataset indicate SDs for the estimated number of phylotypes

tions in cm-sized zones in the sediment. It is possible that the extent of suboxia was even underestimated due to mixing of sulfidic porewater from adjacent zones during sampling of the $200 \mathrm{ml}$ sample.
Measurements of sulfide and oxygen revealed a large degree of horizontal heterogeneity in porewater conditions. This was also evident from the difference in color of the sediment samples from 25 to $35 \mathrm{~cm}$ depth. Sediment porewater transport may be driven by bioturbation or bioirrigation caused by in- or epifaunal activity, or by pressure gradients introduced by water movement and surface topographies. Sandy sediments are characterized by high permeabilities, and pressure-driven advection dominates the porewater transport (Huettel et al. 2003). In shallow sediments the rate of pressure-driven sediment ventilation varies with the wave pattern, and this may result in large temporal variations in porewater redox conditions (Falter \& Sansone 2000a,b). Furthermore, local variations in labile carbon sources and faunal activity may affect rates of oxygen consumption and porewater redox state (Werner et al. 2006). These factors may all contribute to the observed horizontal variation in porewater chemistry.

\section{Microbial community structure}

The detection of phylogenetic groups during DNAbased studies does not necessarily imply an in situ activity. This is because the procedure of DNA extraction and amplification may not distinguish between active, dormant, or dead cells. Furthermore, DNA adsorbed onto sediment particles may be released and co-extracted during sediment manipulations. Bias may also be introduced by the potentially selective extraction and PCR amplification of some phylotypes at the expense of others. In spite of these limitations, phylogenetic studies have been employed successfully as a sensitive tool for following prokaryotic population shifts across temporal and spatial gradients in marine sediments (e.g. Bowman \& McCuaig 2003, Yoza et al. 2007). In this study, the DGGE band pattern was highly reproducible in the surface sediment, but varied among samples from deeper in the sediment. This pattern of increasing heterogeneity with depth is unlikely to be caused by a background of particle-adsorbed DNA and/or inactive cells. Rather, it reflects a spatial diversification of active microbial communities in the geochemically heterogeneous sediment. The decreasing frequencies with depth of Cyanobacteria and increasing frequencies of phylotypes related to anaerobic organisms (like sulfate-reducing Deltaproteobacteria in the 3 clone libraries) also suggest that the extracted DNA reflects to a large degree the active microbial population.

The clone library from 25 to $35 \mathrm{~cm}$ had a significantly higher diversity than similar clone libraries from the surface or from deeper in the sediment. Geochemical 
measurements showed that the sediment at this depth was characterized by frequent redox gradients. These may have allowed for the growth of microorganisms involved in redox cycling of, for example, $\mathrm{S}$ and $\mathrm{N}$ that would not have been favored in the geochemically more homogeneous layers above and below. The increased phylotype richness observed in the clone library from 25 to $35 \mathrm{~cm}$ may thus result from the presence of a metabolically more complex community.

\section{Phylogenetic composition of the microbial community}

With the exception of the new cluster of cyanobacterial relatives, the groups of prokaryotes reported here have all been previously associated with marine sediments. Proteobacteria of the Gamma-, Delta, and Alpha- subdivisions as well as members of the 'Bacteroidetes', 'Chloroflexi', Acidobacteria, Planctomycea, and Actinobacteria are among the most common and numerically abundant groups of Bacteria detected during 16S rRNA gene surveys of marine sediments (e.g. Bowman \& McCuaig 2003, Hunter et al. 2006). Also, Verrucomicrobia, Nitrospira, and Chlamydia have been found previously in marine sediments and water columns (e.g. Asami et al. 2005).

Several order- and phylum-level differences in the composition of clone libraries were observed (Table 1). Cyanobacteria and relatives were abundant in the clone library from the surface, Gammaproteobacteria, Acidobacteria, Planctomycea, and putative nonsulfate-reducing Deltaproteobacteria dominated the clone library from $35 \mathrm{~cm}$ depth, and members of the 'Chloroflexi' and predominantly sulfate-reducing orders of Deltaproteobacteria were abundant in the $75 \mathrm{~cm}$ clone library. The frequency of archaeal phylotypes increased with depth. Only one sample from each depth was selected for cloning and sequencing, and in light of the large horizontal variation, it is not clear whether phylogenetic differences between the 35 and $75 \mathrm{~cm}$ samples reflected a general vertical pattern in the sediment. However, the vertical succession of major groups like Gamma- and Deltaproteobacteria, 'Chloroflexi', and Planctomycea is in agreement with previous studies of other types of sediment (e.g. Bowman \& McCuaig 2003).

The new group of Cyanobacteria-like sequences found in this study was detected in numerous sand samples collected around the island of Oahu (data not shown), indicating a wide distribution in the sediment. The sequences form a monophyletic group that branch near the root of the Cyanobacteria, but with low bootstrap support $(50 \%)$. Because the similarity of these sequences to any previously deposited GENBANK sequences were $<75 \%$, it is not clear whether they represent free-living organisms or a group of eukaryotal chloroplasts or plasmids. Further studies are underway to evaluate the nature and geographical distribution of this group and their role, if any, in the coral reef ecosystem.

Acknowledgements. We thank A. Rusch for help during cell counting, M. Rappé for sponsoring field trips to Coconut Island, and F. Sansone for the use of field equipment. This work was supported in part by NSF Research in Biogeosciences Award EAR 03-11912.

\section{LITERATURE CITED}

Altschul SF (1997) Gapped BLAST and PSI-BLAST: a new generation of protein database search programs. Nucleic Acids Res 25:3389-3402

Asami H, Aida M, Watanabe K (2005) Accelerated sulfur cycle in coastal marine sediment beneath areas of intensive shellfish aquaculture. Appl Environ Microbiol 71: 2925-2933

Ashelford KE, Weightman AJ, Fry JC (2002) PRIMROSE: a computer program for generating and estimating the phylogenetic range for 16S rRNA oligonucleotide probes and primers in conjuncture with the RDP-II database. Nucleic Acids Res 30:3481-3489

Bowman JP, McCuaig RD (2003) Biodiversity, community structural shifts, and biogeography of prokaryotes within Antarctic continental shelf sediment. Appl Environ Microbiol 69:2463-2483

Brendel PJ, Luther GW III (1995) Development of a gold amalgam voltammetric microelectrode for the determination of dissolved $\mathrm{Fe}, \mathrm{Mn}, \mathrm{O} 2$, and $\mathrm{S}(-\mathrm{II})$ in porewaters of marine and freshwater sediments. Environ Sci Technol 29:751-761

Buhring SI, Elvert M, Witte U (2005) The microbial community structure of different permeable sandy sediments characterized by the investigation of bacterial fatty acids and fluorescence in situ hybridization. Environ Microbiol $7: 281-293$

Chen KY, Morris JC (1972) Kinetics of oxidation of aqueous sulfide by $\mathrm{O}_{2}$. Environ Sci Technol 6:529

Delong EF (1998) Everything in moderation: archaea as 'nonextremophiles'. Curr Opin Genet Dev 8:649-654

Dollhopf ME, Nealson KH, Simon DM, Luther GW III (2000) Kinetics of Fe(III) and Mn(IV) reduction by the Black Sea strain of Shewanella putrefaciens using in situ solid state voltammetric $\mathrm{Au} / \mathrm{Hg}$ electrodes. Mar Chem 70:171-180

Falter JL, Sansone FJ (2000a) Shallow pore water sampling in reef sediments. Coral Reefs 19:93-97

Falter JL, Sansone FJ (2000b) Hydraulic control of pore water geochemistry within the oxic-suboxic zone of a permeable sediment. Limnol Oceanogr 45:550-557

Felsenstein J (1988) Phylogenies from molecular sequences: inference and reliability. Annu Rev Genet 22:521-565

Fuhrmann JA, McCallum K, Davis AA (1992) Novel major archaebacterial group from marine plankton. Nature 356: 148-149

Glazer BT, Luther GW III, Konovalov SK, Freiderich GE and 5 others (2006) Documenting the suboxic zone of the Black Sea via high-resolution real-time redox profiling. DeepSea Res II 53:1740-1755

Guyoneaud R, Mouné S, Eatock C, Bothorel V and 7 others (2002) Characterization of three spiral-shaped purple nonsulfur bacteria isolated from coastal lagoon sediments, 
saline sulfur springs, and microbial mats: emended description of the genus Roseospira and description of Roseospira marina sp. nov., Roseospira navarrensis sp. nov., and Roseospira thiosulfatophila sp. nov. Arch Microbiol 178:315-324

Hewson I, Fuhrman JA (2006) Spatial and vertical biogeography of coral reef sediment bacterial and diazotroph communities. Mar Ecol Prog Ser 306:79-86

Hirsch P, Müller M (1985) Planctomyces limnophilus sp. nov., a stalked and budding bacterium from freshwater. Syst Appl Microbiol 6:276-280

Huber T, Faulkner G, Hugenholz P (2004) Bellerophon: a program to detect chimeric sequences in multiple sequence alignments. Bioinformatics 20:2317-2319

Huettel M, Ziebis W, Forster S, Luther GW III (1998) Advective transport affecting metal and nutrient distributions and interfacial fluxes in permeable sediments. Geochim Cosmochim Acta 62:613-631

Huettel M, Røy H, Precht E, Ehrenhauss S (2003) Hydrodynamical impact on biogeochemical processes in aquatic sediments. Hydrobiologia 494:231-236

Hunter EM, Mills HJ, Kostka J (2006) Microbial community diversity associated with carbon and nitrogen cycling in permeable shelf sediments. Appl Environ Microbiol 72: 5689-5701

Imhoff JF (2001) True marine and halophilic anoxygenic phototrophic bacteria. Arch Microbiol 176:243-254

Jokiel PL, Hunter CL, Taguchi S, Watarai L (1993) Ecological impact of a freshwater 'reef kill' in Kaneohe Bay, Oahu, Hawaii. Coral Reefs 12:177-184

Kemp PF, Aller JY (2004) Bacterial diversity in aquatic and other environments: what 16S rDNA libraries can tell us. FEMS Microbiol Ecol 47:161-177

Könneke M, Bernhard AE, de la Torre JR, Walker CB, Waterbury JB, Stahl DA (2005). Isolation of an autotrophic ammonia-oxidizing marine archaeon. Nature 437: 543-546

Luther GW III, Brendel PJ, Lewis BL, Sundby B, Lefrancois BL, Silverberg N, Nuzzio DB (1998) Simultaneous measurement of $\mathrm{O}_{2}, \mathrm{Mn}, \mathrm{Fe}, \mathrm{I}$, and $\mathrm{S}(-\mathrm{II})$ in marine pore waters with a solid-state voltammetric microelectrode. Limnol Oceanogr 43:325-333

Marinelli RL, Jahnke RA, Craven DB, Nelson JR, Eckman JE (1998) Sediment nutrient dynamics on the South Atlantic Bight continental shelf. Limnol Oceanogr 43:1305-1320

Muyzer G, de Waal EC, Uitterlinden AG (1993) Profiling of complex microbial populations by denaturing gradient gel electrophoresis analysis of polymerase chain reactionamplified genes coding for 16S rRNA. Appl Environ Microbiol 59:695-700

Porter KC, Feig YS (1980) The use of DAPI for identifying and counting aquatic microflora. Limnol Oceanogr 25:943-948

Rasheed M, Badran MI, Huettel M (2003) Particulate matter filtration and seasonal nutrient dynamics in permeable carbonate and silicate sands of the Gulf of Aqaba, Red

Editorial responsibility: Otto Kinne (Editor-in-Chief), Oldendorf/Luhe, Germany
Sea. Coral Reefs 22:167-177

Rasheed M, Wild C, Franke U, Huettel M (2004) Benthic photosynthesis and oxygen consumption in permeable carbonate sediments at Heron Island, Great Barrier Reef, Australia. Estuar Coast Shelf Sci 59:139-150

Sanford RA, Cole JR, Tiedje JM (2002) Characterization and description of Anaeromyxobacter dehalogenans gen. nov., sp nov., an aryl-halorespiring facultative anaerobic myxobacterium. Appl Environ Microbiol 68:893-900

Schlesner H (1986) Pirella marina sp. nov., a budding, peptidoglycan-less bacterium from brackish water. Syst Appl Microbiol 8:177-180

Shashar N, Feldstein T, Cohen Y, Loya Y (1994) Nitrogen fixation (acetylene reduction) on a coral reef. Coral Reefs 13: 171-174

Sorokin DY, Lysenko AM, Mityushina LL, Tourova TP, Jones BE, Rainey FA, Robertson LA, Kuenen GJ (2001) Thioalkalimicrobium aerophilum gen. nov., sp. nov. and Thioalkalimicrobium sibericum sp. nov., and Thioalkalivibrio versutus gen. nov., sp. nov., Thioalkalivibrio nitratis sp. nov. and Thioalkalivibrio denitrificans sp. nov., novel obligately alkaliphilic and obligately chemolithoautotrophic sulfur-oxidizing bacteria from soda lakes. Int J Syst Evol Microbiol 51:565-580

Takai K, Moser DP, DeFlaun M, Onstott TC, Fredrickson JK (2001) Archaeal diversity in waters from deep South African gold mines. Appl Environ Microbiol 67:5750-5760

Thompson JD, Higgins DG, Gibson TJ (1994) CLUSTAL W: improving the sensitivity of progressive multiple sequence alignment through sequence weighting, position-specific gap penalties and weight matrix choice. Nucleic Acids Res 22:4673-4680

Thompson JR, Marcelino LA, Polz MF (2002) Heteroduplexes in mixed-template amplifications: formation, consequence and elimination by 'reconditioning PCR'. Nucleic Acids Res 30:2083-2088

Werner U, Bird P, Wild C, Ferdelman T and 5 others (2006) Spatial patterns of aerobic and anaerobic mineralization rates and oxygen penetration dynamics in coral reef sediments. Mar Ecol Prog Ser 309:93-105

Wild C, Rasheed M, Werner U, Franke U, Johnstone R, Huettel M (2004) Degradation and mineralization of coral mucus in reef environments. Mar Ecol Prog Ser 267: 159-171

Wild C, Laforsch C, Huettel M (2006) Detection and enumeration of microbial cells within highly porous calcareous reef sands. Mar Freshw Res 57:415-420

Yamamoto N, Lopez G (1985) Bacterial abundance in relation to surface area and organic content of marine sediments. J Exp Mar Biol Ecol 90:209-220

Yoza BA, Harada RM, Nihous GC, Li QX, Masutani SM (2007) Impact of mariculture on microbial diversity in sediments near open ocean farming of Polydactylus sexfilis. Ecol Indicators 7:108-122

Submitted: October 20, 2006; Accepted: March 21, 2007

Proofs received from author(s): September 6, 2007 